\title{
3-Formylindole-4-aminobenzoic Acid: A Potential Corrosion Inhibitor for Mild Steel and Copper in Hydrochloric Acid Media
}

\author{
Aby Paul, Joby Thomas K., Vinod P. Raphael, and K. S. Shaju \\ Research Division, Department of Chemistry, St. Thomas' College, University of Calicut, Thrissur 680001, India \\ Correspondence should be addressed to Joby Thomas K., drjobythomask@gmail.com \\ Received 19 September 2012; Accepted 2 October 2012 \\ Academic Editors: C. Gu, A. Hermann, C.-H. Hsu, G. Marginean, and C. Valentini \\ Copyright () 2012 Aby Paul et al. This is an open access article distributed under the Creative Commons Attribution License, \\ which permits unrestricted use, distribution, and reproduction in any medium, provided the original work is properly cited. \\ The corrosion inhibition efficiencies of Schiff base 3-formylindole-4-aminobenzoic acid (3FI4ABA) on mild steel (MS) and copper \\ in $1.0 \mathrm{M} \mathrm{HCl}$ solution have been investigated using weight loss measurements, electrochemical impedance spectroscopy (EIS) and \\ potentiodynamic polarization studies. The results show that inhibition efficiencies on both metals increase with increasing the \\ concentration of the inhibitor. 3FI4ABA exhibited comparatively good inhibition towards mild steel in $\mathrm{HCl}$ medium even at low \\ concentrations. The adsorption of inhibitor on the surfaces of the corroding metal mild steel and copper obeys the Langmuir \\ isotherm. Polarization studies revealed that 3 FI4ABA acts as a mixed-type inhibitor. Thermodynamic parameters $\left(K_{\text {ads }}, \Delta G_{\text {ads }}^{0}\right)$ \\ were calculated using the Langmuir adsorption isotherm.
}

\section{Introduction}

Schiff bases are organic molecules possessing azomethine linkage $(\mathrm{C}=\mathrm{N})$ and have innumerable advantages, right from pharmaceutical applications to the corrosion inhibitions, in the various fields of science. The heteroatoms present in these molecules are of key importance and are responsible for the corrosion inhibition in acidic media on the metal surface [1-3]. Some recently reported Schiff bases showed effective inhibition for mild steel (MS), aluminum, copper, and zinc in acidic media [4-11].

The study on MS and copper corrosion has become much important particularly in industrial and academic fields. Enormous use of hydrochloric acid for acid pickling, descaling, and cleaning process of mild steel surface are the major reasons for the corrosion problems in the world. Increasing efforts have been made to study the corrosion behavior of metals and mechanism of inhibition during the past decade mainly through electrochemical investigations [8, 9]. Limited work has been reported for the corrosion inhibition of compounds derived from 3 -formylindole in acid media. The present investigation was undertaken to examine the corrosion inhibition capacity and mechanism of inhibition of a novel heterocyclic Schiff base (3FI4ABA) molecules derived from 3-formylindole and 4-aminobenzoic acid in $1 \mathrm{M} \mathrm{HCl}$ solution on MS and Copper. The study was performed using weight loss measurements, electrochemical impedance spectroscopy (EIS), and potentiodynamic polarization analysis.

\section{Experimental}

2.1. Inhibitor. Heterocyclic Schiff base was obtained by the condensation of equimolar mixture of 3-formylindole and 4 -amino benzoic acid in ethanol. The reaction mixture was refluxed for 2 hours, evaporated and cooled in ice bath to obtain yellow coloured compound. Figure 1 shows the molecular structure of heterocyclic Schiff base 3FI4ABA. Anal.calcd for $\mathrm{C}_{16} \mathrm{H}_{12} \mathrm{~N}_{2} \mathrm{O}_{2}$ : C, 72.72; $\mathrm{H}, 4.55 ; \mathrm{N}, 10.61 ; \mathrm{O}$, $12.12 \%$. Found. C, 67.96; H, 5.03; N, 9.95; O, 12.12\%; m.p. = $151^{\circ} \mathrm{C}$; IR $(\mathrm{KBr}): v_{\mathrm{C}=\mathrm{N}}=1559 \mathrm{~cm}^{-1} .{ }^{1} \mathrm{Hnmr}: \delta_{\mathrm{COOH}} 12.15$, $\delta_{\mathrm{CH}=\mathrm{N}} 9.94, \delta_{\mathrm{NH}} 5.59 .{ }^{13} \mathrm{Cnmr}: \delta_{\mathrm{COOH}} 184.93, \delta_{\mathrm{CH}=\mathrm{N}} 131.2$. Mass: $\mathrm{M}^{+}$peak absent, base peak m/z: 144 .

2.2. Solutions. The aggressive solutions of $1 \mathrm{M} \mathrm{HCl}$ were prepared by dilution of $\mathrm{AR}$ grade $37 \%$ of $\mathrm{HCl}$ (Merck) with deionized water. Inhibitor solutions were prepared in the range, $0.1 \mathrm{mM}-1 \mathrm{mM}$ concentrations.

2.3. Weight Loss Measurements. Mild steel specimens and copper specimens of dimension $1.5 \times 2 \times 0.1 \mathrm{~cm}$ were cut abraded with various grades of silicon carbide papers 


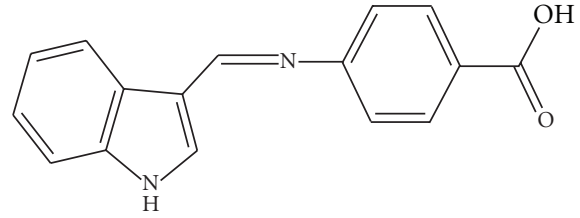

Figure 1: Molecular structure of 3FI4ABA.

$(200,400,600,800,1000,1200$, and 2000). The exact area and thickness of each coupon were measured and washed with distilled water containing detergent. Specimens were then degreased again with acetone and finally dried. After weighing with sensitive electronic balance, specimens were immersed in $50 \mathrm{ml}$ acid solutions (nondeaerated) at $28^{\circ} \mathrm{C}$ in the absence and presence of the inhibitor, 3FI4ABA, using hooks and fishing lines. Weight loss of metal specimens was noted for five consecutive days at $24 \mathrm{~h}$ interval. The experiments were carried out in duplicate, and the average values were reported. The corrosion rate $(\nu)$ is calculated by the following equation [8]:

$$
v=\frac{W}{S t},
$$

where $W$ is the average weight loss of coupon, $S$ is the total area of specimens, and $t$ is the time of treatment $(24,48,72$, 96 , and $120 \mathrm{hrs})$. The percentage of inhibition efficiency $(\eta)$ is defined by [12]:

$$
\eta_{w} \%=\frac{\nu_{0}-\nu}{v_{0}} \times 100
$$

where $v_{0}$ and $v$ are the corrosion rates of uninhibited and inhibited specimens, respectively.

2.4. Electrochemical Impedance Spectroscopy (EIS). The EIS measurements were performed in a three-electrode assembly. Saturated calomel electrode (SCE) was used as the reference electrode. Platinum electrode having $1 \mathrm{~cm}^{2}$ area was taken as counter electrode. Metal specimens with an exposed area of $1 \mathrm{~cm}^{2}$ were used as the working electrode. The EIS experiments were carried out on a Ivium compactSstat-e electrochemical system. $1 \mathrm{M} \mathrm{HCl}$ acid (no deaeration, no stirring) was taken as the electrolyte, and the working area of the metal specimens was exposed to the electrolyte for $1 \mathrm{~h}$ prior to the measurement. EIS measurements were performed at constant potential (OCP) in the frequency range of $1 \mathrm{KHz}$ to $100 \mathrm{mHz}$ with amplitude of $10 \mathrm{mV}$ as excitation signal. The percentage of inhibitions from impedance measurements was calculated using charge transfer resistance values by the following expression [2]:

$$
\eta_{\mathrm{EIS}} \%=\frac{R_{\mathrm{ct}}-R_{\mathrm{ct}}^{\prime}}{R_{\mathrm{ct}}} \times 100,
$$

where $R_{\mathrm{ct}}$ and $R_{\text {ct }}^{\prime}$ are the charge transfer resistances of working electrode with and without inhibitor, respectively.

2.5. Potentiodynamic Polarization. Electrochemical polarization studies of MS and copper specimens in $1 \mathrm{M} \mathrm{HCl}$ with and without inhibitor were performed by recording anodic and cathodic potentiodynamic polarization curves. Polarization plots were obtained in the electrode potential range of -100 to $+100 \mathrm{mV}$ Vs corrosion potential $\left(E_{\mathrm{corr}}\right)$ at a scan rate of $1 \mathrm{mV} / \mathrm{sec}$. Tafel polarization analyses were done by extrapolating anodic and cathodic curves to the potential axis to obtain corrosion current densities $\left(I_{\text {corr }}\right)$. The percentage of inhibition efficiency $\left(\eta_{\mathrm{pol}} \%\right)$ was evaluated from the measured $I_{\text {corr }}$ values using the following relation [13]:

$$
\eta_{\text {pol }} \%=\frac{I_{\text {corr }}-I_{\text {corr }}^{\prime}}{I_{\text {corr }}} \times 100,
$$

where $I_{\text {corr }}$ and $I^{\prime}$ corr are the corrosion current densities of the exposed area of the working electrode in the absence and presence of inhibitor.

From the slope analysis of the linear polarization curves in the vicinity of corrosion potential of blank and different concentrations of the inhibitor, the values of polarization resistance $\left(R_{p}\right)$ in $1 \mathrm{M} \mathrm{HCl}$ solution were obtained. From the evaluated polarization resistance, the inhibition efficiency was calculated using the relationship:

$$
\eta_{R p} \%=\frac{R_{p}^{\prime}-R_{p}}{R_{p}^{\prime}} \times 100,
$$

where $R_{p}^{\prime}$ and $R_{p}$ are the polarization resistance in the presence and absence of inhibitor, respectively [2].

\section{Results and Discussions}

3.1. Weight Loss Measurements. Weight loss of MS and copper specimens in $1 \mathrm{M} \mathrm{HCl}$ was determined at $24 \mathrm{~h}$ interval for a period of five days in the presence of various concentrations of inhibitor. The corrosion rates and inhibition efficiencies obtained for MS and copper specimens for a period of $24 \mathrm{~h}$ are listed in Tables 1(a) and 1(b), respectively. For MS specimens, the corrosion rate markedly decreased with inhibitor concentration from 0 to $0.4 \mathrm{mM}$. This response is due to the fact that the surface coverage of the inhibitor molecules on the metal through adsorption increases with the increase in concentration [14]. From $0.5 \mathrm{mM}$ to $0.7 \mathrm{mM}$ inhibitor concentration, percentage of inhibition efficiencies showed a gradual rise. A maximum inhibition efficiency of $88.7 \%$ was obtained for $0.7 \mathrm{mM}$. Beyond this concentration, $\eta_{W} \%$ got a saturation character and did not change noticeably. Figures 2 and 3 portrait the variation of rates of corrosion and inhibition efficiencies of MS specimens with immersion period. For a given period of immersion, the corrosion rate initially decreased considerably with inhibitor concentration and reached a minimum. As the concentration of 3FI4ABA increased, a marked rise in the inhibition efficiency was observed. The inhibition efficiency showed a saturation value at the inhibitor concentration $0.7 \mathrm{mM}$ (critical inhibitor concentration) $[15,16]$.

Table 1 (b) reveals the corrosion rates and inhibition efficiencies of 3FI4ABA for copper specimens in $1 \mathrm{M} \mathrm{HCl}$. Apart from the corrosion behavior of MS specimens, copper specimens showed low corrosion rates and inhibition efficiencies for the same concentrations of inhibitor except 
TABLE 1: The corrosion rate and percentage of inhibition efficiency obtained for (a) MS specimens and (b) Cu specimens immersed in $1 \mathrm{M} \mathrm{HCl}$ at $28^{\circ} \mathrm{C}$ for $24 \mathrm{~h}$ in the presence and absence of 3FI4ABA.

(a)

\begin{tabular}{lcc}
\hline$C(\mathrm{mM})$ & Corrosion rate $\left(\mathrm{mmy}^{-1}\right)$ & Inhibition effiiency $\left(\eta_{W} \%\right)$ \\
\hline 0 & 9.11 & - \\
0.1 & 5.31 & 41.71 \\
0.2 & 2.86 & 68.58 \\
0.3 & 2.18 & 76.01 \\
0.4 & 1.55 & 82.94 \\
0.5 & 1.31 & 85.58 \\
0.6 & 1.10 & 87.86 \\
0.7 & 1.03 & 88.69 \\
0.8 & 1.05 & 88.40 \\
\hline
\end{tabular}

(b)

\begin{tabular}{lcc}
\hline$C(\mathrm{mM})$ & Corrosion rate $\left(\mathrm{mmy}^{-1}\right)$ & Inhibition efficiency $\left(\eta_{W} \%\right)$ \\
\hline 0 & 0.6002 & - \\
0.1 & 0.2400 & 60.0 \\
0.2 & 0.2315 & 61.4 \\
0.3 & 0.2300 & 61.7 \\
0.4 & 0.2280 & 62.0 \\
0.5 & 0.2203 & 63.3 \\
0.6 & 0.2187 & 63.6 \\
0.7 & 0.2141 & 64.3 \\
0.8 & 0.2045 & 65.9 \\
\hline
\end{tabular}

for $0.1 \mathrm{mM}$. At this lower concentration, a noticeable value of $\eta_{W} \%$ was obtained for copper specimens, suggesting that 3FI4ABA molecules are fairly adsorbed on the surface of the metal. Beyond this concentration, only gradual rise in the inhibition efficiency was observed, and a maximum of $66 \%$ was obtained for 3FI4ABA concentration $0.8 \mathrm{mM}$. Low values of $\eta_{W} \%$ can be attributed to the formation of stable complex between the 3FI4ABA molecules and $\mathrm{Cu}^{2+}$ ions produced by corrosion. The desorption of 3FI4ABA molecules may be favored by the great affinity of inhibitor molecules to copper ions. The presence of green coloured copper complex inside the experiment vessels is the supporting evidence of this argument.

The variation of corrosion rates and inhibition efficiencies with immersion time are represented in Figures 4 and 5. Almost a similar trend to that of MS specimens was observed for copper specimens.

3.2. Comparison of Inhibition Efficiency of Schiff Base with Its Parent Amine. To compare the inhibition efficiencies of Schiff base and parent amine, weight loss measurements of MS specimens and copper specimens were performed in $1 \mathrm{M} \mathrm{HCl}$ at $28^{\circ} \mathrm{C}$. The percentage of corrosion inhibition efficiencies obtained for Schiff base and parent amine on MS and copper specimens are listed in Table 2. For MS specimens, the inhibition efficiency of the Schiff base 3FI4ABA was markedly higher than that of 4-aminobenzoic acid for the studied concentrations. For copper specimens fair inhibition

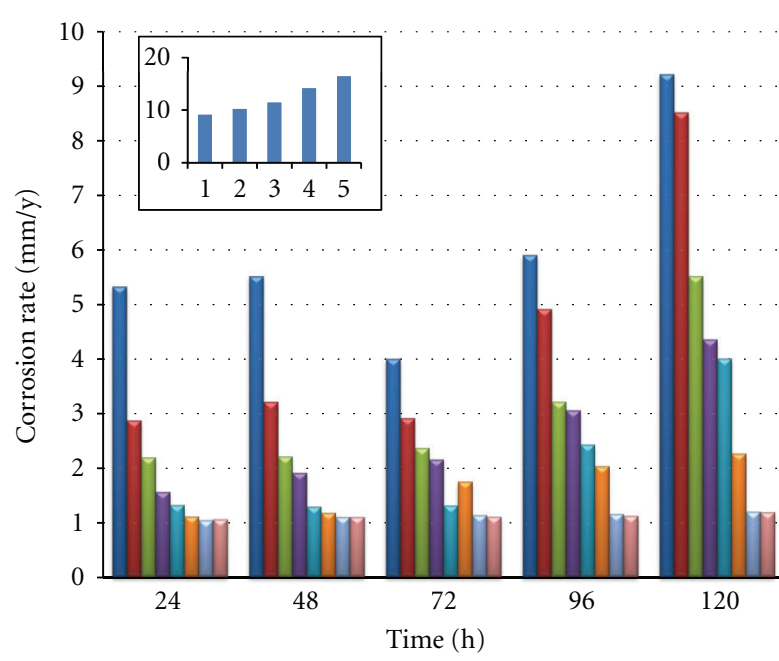

$$
\begin{array}{rlrl}
\square \text { Series } 1=0.1 \mathrm{mM} & \square \text { Series } 5 & =0.5 \mathrm{mM} \\
\square \text { Series } 2=0.2 \mathrm{mM} & \square \text { Series } 6=0.6 \mathrm{mM} \\
\square \text { Series } 3=0.3 \mathrm{mM} & \square \text { Series } 7=0.7 \mathrm{mM} \\
\square \text { Series } 4=0.4 \mathrm{mM} & \square \text { Series } 8=0.8 \mathrm{mM}
\end{array}
$$

FIGURE 2: Variation of corrosion rate with immersion time of MS specimens in $1 \mathrm{M} \mathrm{HCl}$ with various inhibitor concentrations.

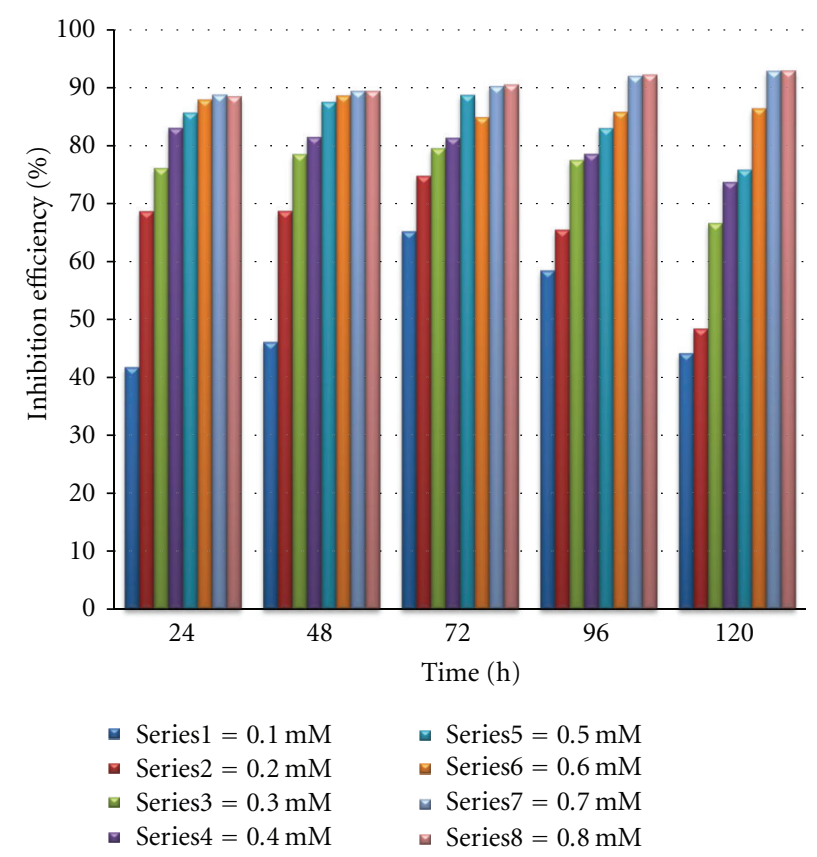

FIGURE 3: Variation of $\eta_{W} \%$ with immersion time of MS specimens in $1 \mathrm{M} \mathrm{HCl}$ in different inhibitor concentrations.

efficiencies were observed for the Schiff base than the parent amine. This investigation clearly establishes the role of azomethine linkage $(\mathrm{C}=\mathrm{N})$ present in the Schiff base, which actively participates in the corrosion inhibition mechanism.

3.3. Adsorption Isotherm and Free Energy of Adsorption. The mechanism of adsorption and the surface behavior of organic molecules can be easily viewed through adsorption 


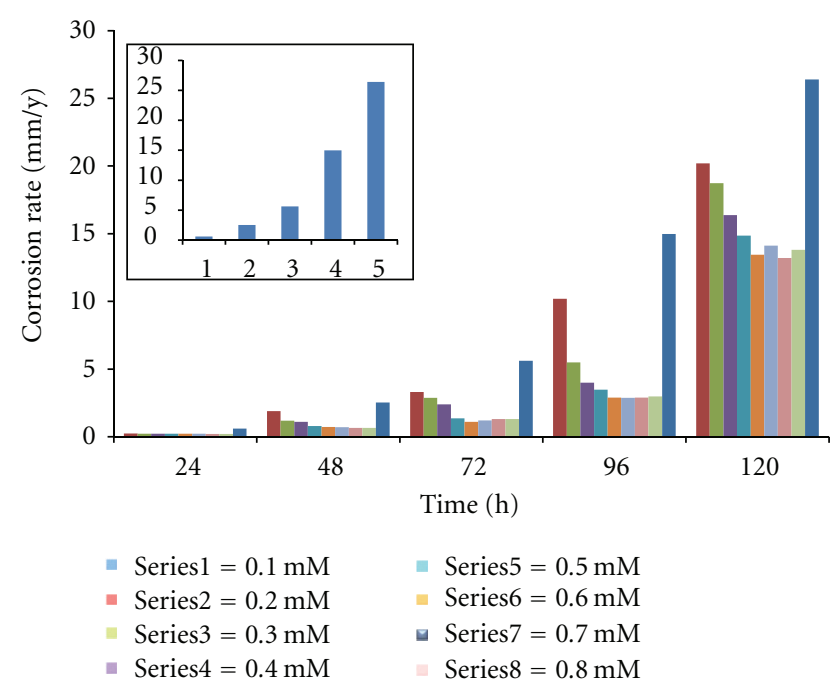

Figure 4: Variation of corrosion rate with immersion time of copper specimens in $1 \mathrm{M} \mathrm{HCl}$ with various inhibitor concentrations.

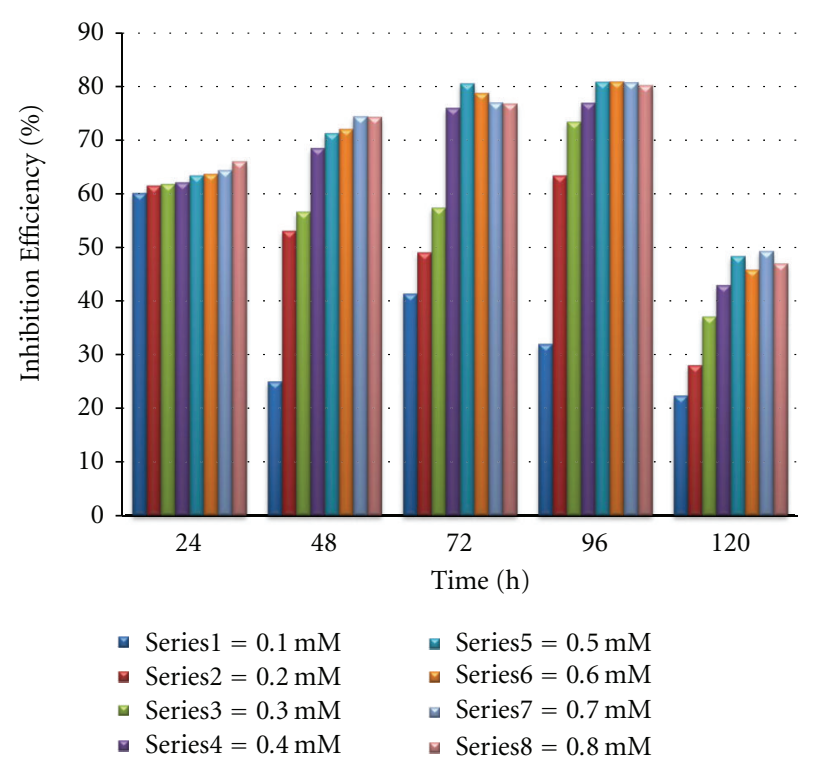

Figure 5: Variation of $\eta_{W} \%$ with immersion time of copper specimens in $1 \mathrm{M} \mathrm{HCl}$ with various inhibitor concentrations.

isotherms. Different models of adsorption isotherms considered are Langmuir, Temkin, Frumkin, and Freundlich isotherms. For the evaluation of thermodynamic parameters, it is necessary to determine the best-fit isotherm with the aid of correlation coefficient $\left(R^{2}\right)$. Among the isotherms mentioned above, the best description of the adsorption behavior of 3FI4ABA on MS specimens and copper specimens in $1 \mathrm{M} \mathrm{HCl}$ was Langmuirs adsorption isotherm which can be expressed as

$$
\frac{C}{\theta}=\frac{1}{K_{\mathrm{ads}}}+C
$$

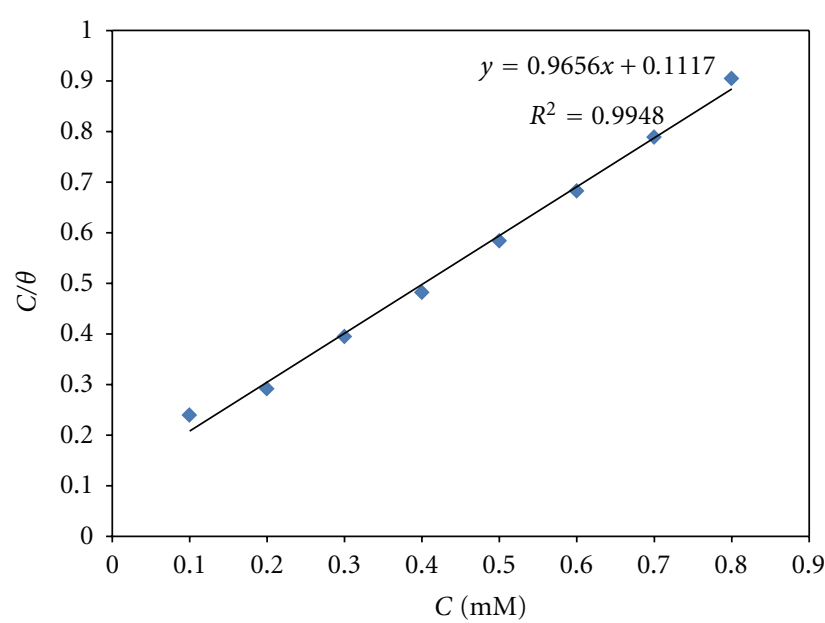

Figure 6: The Langmuir adsorption isotherm for adsorption of 3FI4ABA on MS surface in $1 \mathrm{M} \mathrm{HCl}$ at $28^{\circ} \mathrm{C}$.

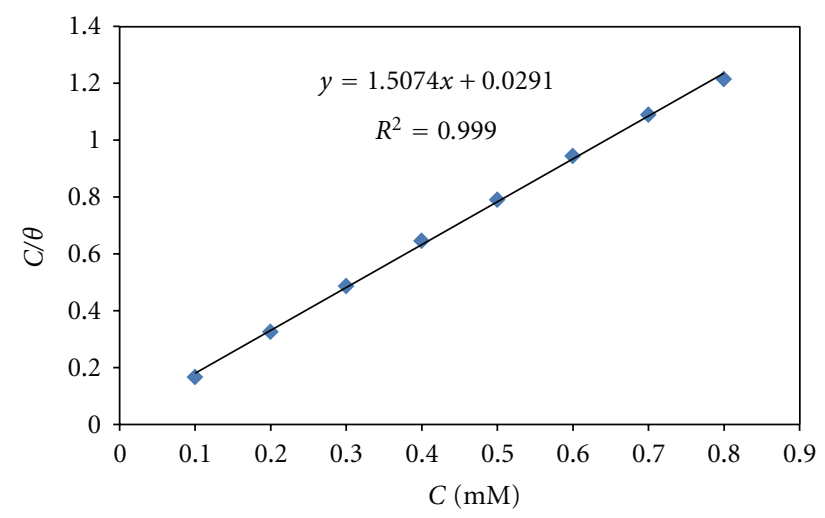

Figure 7: The Langmuir adsorption isotherm of 3FI4ABA on copper surface in $1 \mathrm{M} \mathrm{HCl}$ at $28^{\circ} \mathrm{C}$.

where $C$ is the concentration of the inhibitor, $\theta$ is the fractional surface coverage, and $K_{\text {ads }}$ is the adsorption equilibrium constant [17].

Figures 6 and 7 represents the adsorption plots of 3FI4ABA obtained by the weight loss measurements of MS steel specimens and copper specimens in $1 \mathrm{M} \mathrm{HCl}$ at $28^{\circ} \mathrm{C}$.

The adsorption equilibrium constant $K_{\mathrm{ads}}$ is related to the standard free energy of adsorption $\Delta G_{\text {ads }}^{0}$, by

$$
\Delta G_{\mathrm{ads}}^{0}=-R T \ln \left(55.5 K_{\mathrm{ads}}\right),
$$

where 55.5 is the molar concentration of water, $R$ is the universal gas constant, and $T$ is the temperature in Kelvin [18]. Table 3 explores thermodynamic parameters obtained from weight loss measurements of MS and copper specimens in $1 \mathrm{M} \mathrm{HCl} . \Delta G_{\mathrm{ads}}^{0}$ for 3FI4ABA on MS and copper showed negative values, indicating the spontaneity of the process. The value of $\Delta G_{\mathrm{ads}}^{0}$ up to $-20 \mathrm{~kJ} \mathrm{~mol}^{-1}$ is an indication of the electrostatic interaction of the charged molecule and the charged surface of the metal (physisorption); while $\Delta G_{\mathrm{ads}}^{0}$ is more negative than $-40 \mathrm{~kJ}$ implies that inhibitor molecules are adsorbed strongly on the metal surface through coordinate type bond (chemisorptions [18-20]). In the present 
TABle 2: Comparison of inhibition efficiency of Schiff base and parent amine.

\begin{tabular}{lcccc}
\hline \multirow{2}{*}{$C(\mathrm{mM})$} & \multicolumn{2}{c}{ MS specimens $\left(\eta_{W} \%\right)$} & \multicolumn{2}{c}{ Copper specimens $\left(\eta_{W} \%\right)$} \\
& Parent amine & Schiff base & Parent amine & Schiff base \\
\hline 0.2 & -29.39 & 68.58 & 52.47 & 61.4 \\
0.5 & -18.02 & 85.58 & 54.82 & 65.9 \\
0.8 & -8.16 & 88.40 & 54.70 & 63.3 \\
\hline
\end{tabular}

TABle 3: Thermodynamic parameters obtained from weight loss studies.

\begin{tabular}{lcc}
\hline 3FI4ABA on & $K_{\mathrm{ads}}$ & $\Delta G_{\mathrm{ads}}^{\circ}(\mathrm{kJ} / \mathrm{mol})$ \\
\hline $\mathrm{MS}$ & 8333 & -33.2 \\
$\mathrm{Cu}$ & 33333 & -36.3 \\
\hline
\end{tabular}

investigation, 3FI4ABA molecules showed $\Delta G_{\mathrm{ads}}^{0}-33.2$ and -36.3 , respectively for MS and copper specimens, suggesting that the adsorption of inhibitor involves both electrostatic adsorption and chemisorption.

3.4. EIS Measurements. The corrosion response of MS and copper in $1 \mathrm{M} \mathrm{HCl}$ in the presence and absence of inhibitor has been investigated using electrochemical impedance spectroscopy at $28^{\circ} \mathrm{C}$. Figures 8 and 9 represent the Nyquist plots of MS specimens and copper specimens in $1 \mathrm{M} \mathrm{HCl}$, respectively. It is evident from the plots that the impedance response of metal specimens showed a marked difference in the presence and absence of the inhibitor 3FI4ABA.

The semicircles are observed to be depressed to the $z^{\prime}$ (real) axis or showed slight irregularity which may be attributed to the roughness or nonhomogeneous nature of the metal surface [21-24]. The capacitance loop intersects the real axis at higher and lower frequencies. At highfrequency end, the intercept corresponds to the solution resistance $\left(R_{s}\right)$ and at lower-frequency end corresponds to the sum of $R_{s}$ and charge transfer resistance $\left(R_{\mathrm{ct}}\right)$. The difference between the two values gives $R_{\mathrm{ct}}$. The value of $R_{\mathrm{ct}}$ is a measure of electron transfer across the exposed area of the metal surface and it is inversely proportional to the rate of corrosion [25].

Impedance behaviour can be well explained by pure electric models that could verify and enable calculating numerical values corresponding to the physical and chemical properties of electrochemical system under examination [26]. The simple equivalent circuit that fits to many electrochemical system is composed of a double-layer capacitance, $R_{s}$ and $R_{\mathrm{ct}}$ $[5,27,28]$. To reduce the effects due to surface irregularities of metal, constant phase element (CPE) is introduced into the circuit instead of a pure double-layer capacitance which gives more accurate fit as shown in Figure 10 [29].

The impedance of CPE can be expressed as

$$
Z_{\mathrm{CPE}}=\frac{1}{Y_{0}(j \omega)^{n}},
$$

where $Y_{0}$ is the magnitude of CPE, $n$ is the exponent (phase shift), $\omega$ is the angular frequency, and $j$ is the imaginary unit.
TABLE 4: Electrochemical impedance parameters of (a) MS specimens and (b) copper specimens in $1 \mathrm{M} \mathrm{HCl}$ at $28^{\circ} \mathrm{C}$ in the absence and presence of 3FI4ABA.

(a)

\begin{tabular}{lcccc}
\hline$C(\mathrm{mM})$ & $R_{\mathrm{ct}}\left(\Omega \mathrm{cm}^{2}\right)$ & $C_{\mathrm{dl}}\left(\mu \mathrm{F} \mathrm{cm}^{-2}\right)$ & $R_{s}\left(\Omega \mathrm{cm}^{2}\right)$ & $\eta_{\mathrm{EIS}} \%$ \\
\hline 0 & 10.8 & 102 & 3.78 & - \\
0.2 & 23 & 76 & 5.0 & 53 \\
0.5 & 65 & 80.6 & 11.6 & 83.4 \\
0.7 & 203.2 & 66.9 & 15.2 & 94.7 \\
0.8 & 478 & 53.6 & 21.9 & 97.7 \\
\hline
\end{tabular}

(b)

\begin{tabular}{lcccc}
\hline$C(\mathrm{mM})$ & $R_{\mathrm{ct}}\left(\Omega \mathrm{cm}^{2}\right)$ & $C_{\mathrm{dl}}\left(\mu \mathrm{F} \mathrm{cm}^{-2}\right)$ & $R_{s}\left(\Omega \mathrm{cm}^{2}\right)$ & $\eta_{\mathrm{EIS}} \%$ \\
\hline 0 & 144 & 760 & 16.2 & - \\
0.2 & 345 & 370 & 42 & 58 \\
0.5 & 525 & 475 & 31.1 & 72.5 \\
0.7 & 553 & 267 & 46.3 & 74 \\
0.8 & 919 & 228 & 92.1 & 84 \\
\hline
\end{tabular}

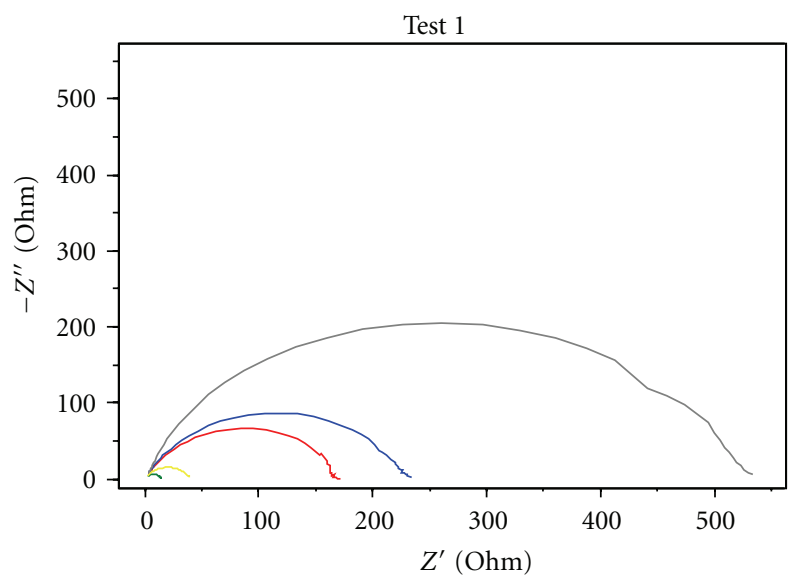

Green: blank Blue: $0.5 \mathrm{mM}$

Yellow: $0.2 \mathrm{mM} \quad$ Grey: $0.8 \mathrm{mM}$

Figure 8: Nyquist plots for MS in $1 \mathrm{M} \mathrm{HCl}$.

CPE may be resistance, capacitance and inductance depending upon the values of $n$ [5]. In all experiments, the observed value of $n$ ranges between 0.8 and 1.0, suggesting the capacitive response of CPE. The EIS parameters such as $R_{\mathrm{ct}}$, $R_{s}$, and CPE and the calculated values of percentage of inhibition $\left(\eta_{\mathrm{EIS}} \%\right)$ of MS specimens and copper specimens are, respectively, listed in Tables 4(a) and 4(b).

From Tables 4(a) and 4(b) it is clear that $R_{\mathrm{ct}}$ values are increased with increasing inhibitor concentration. Decrease in capacitance values $C_{\mathrm{dl}}$ with inhibitor concentration can be attributed to the decrease in local dielectric constant and/or increase in the thickness of the electrical double layer. This emphasizes the action of inhibitor molecules by adsorption at the metal-solution interface [30]. In the case of MS specimens and copper specimens in $1 \mathrm{M} \mathrm{HCl}$, the percentage of inhibitions $\left(\eta_{\mathrm{EIS}} \%\right)$ showed a regular increase with increasing the inhibitor concentration. A maximum of $98 \%$ inhibition 


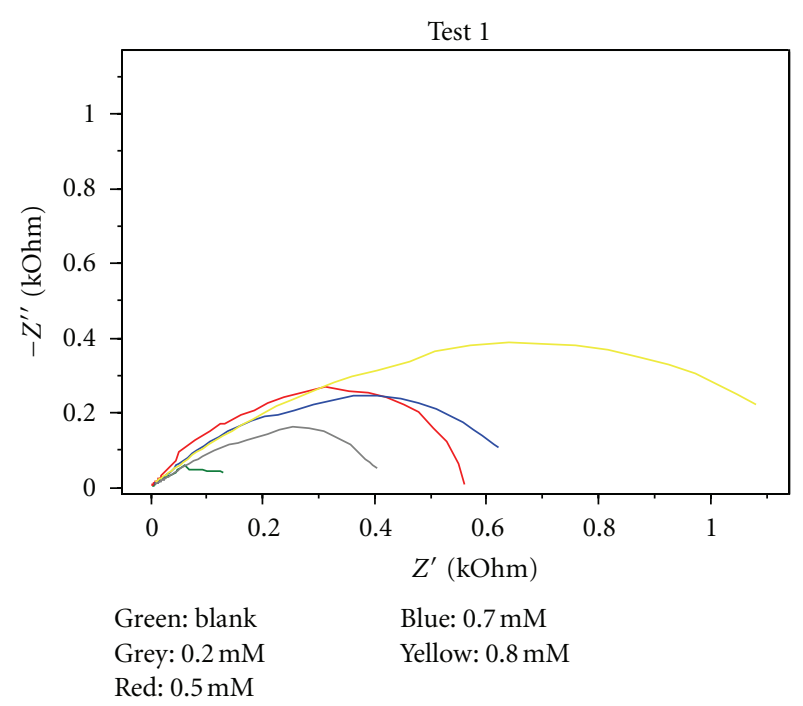

Figure 9: Nyquist plots for $\mathrm{Cu}$ in $1 \mathrm{M} \mathrm{HCl}$.

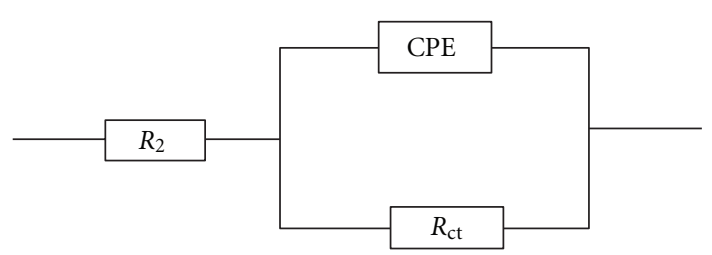

FIGURE 10: Equivalent circuit fitting for EIS measurements.

efficiency could be achieved at an inhibitor concentration of $1 \mathrm{mM}$ for MS specimen. The $\eta_{\mathrm{EIS}} \%$ data reveal that the corrosion inhibition capacity of 3FI4ABA is comparatively greater for MS than copper, which may be attributed to the high rate of desorption of the inhibitor molecules from the Cu surface.

3.5. Potentiodynamic Polarization Studies. Potentiodynamic polarization curves for 3FI4ABA in $1 \mathrm{M} \mathrm{HCl}$ for MS specimens and copper specimens are shown in Figures 11 and 12, respectively.

Polarization parameters like corrosion current densities $\left(I_{\text {corr }}\right)$, corrosion potential $\left(E_{\text {corr }}\right)$, cathodic Tafel slope $\left(b_{c}\right)$, anodic Tafel slope $\left(b_{a}\right)$, and inhibition efficiency $\left(E_{p}\right)$ for MS and copper specimens are listed in Tables 5 and 6 , respectively. In the case of MS specimens, a prominent decrease in the corrosion current density $\left(I_{\text {corr }}\right)$ was observed in the presence of inhibitor 3FI4ABA. A lowest value of $I_{\text {corr }}$ was noticed for the inhibitor solution of concentration $0.8 \mathrm{mM}$, which exhibited a maximum inhibition efficiency of $98 \%$. Since the value of $b_{c}$ changes appreciably in the presence of 3FI4ABA, it may be assumed that the inhibitor molecules are more adsorbed on cathodic sites. Generally, if the shift of $E_{\text {corr }}$ is $>85$ with respect to $E_{\text {corr }}$ of uninhibited solution, the inhibitor can be viewed as cathodic or anodic type $[20,31,32]$. In the present study, the maximum shift of $E_{\text {corr }}$ is $14 \mathrm{mV}$, suggesting that 3FI4ABA acts as a mixed-type

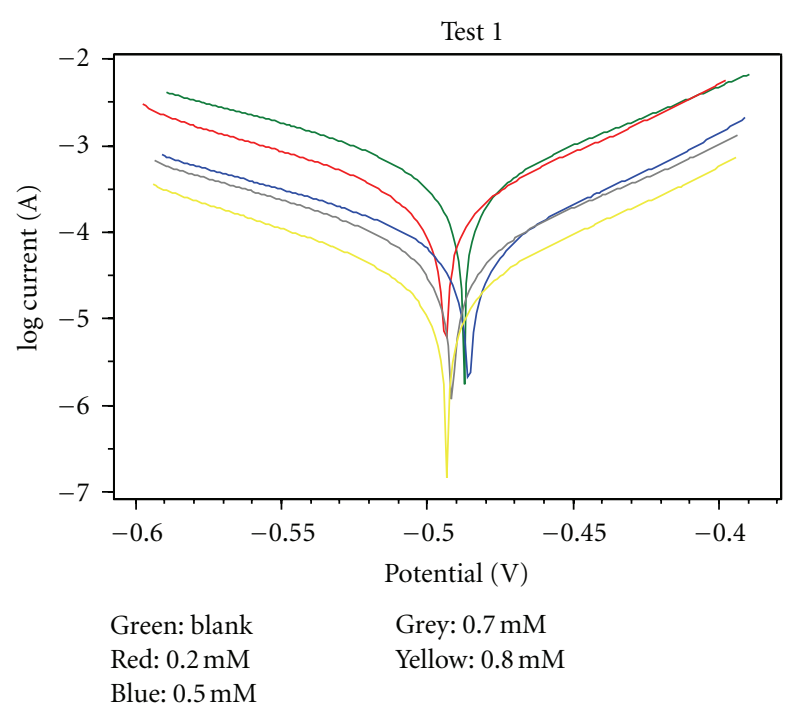

Figure 11: Tafel plots of MS specimens in $1 \mathrm{M} \mathrm{HCl}$ at $28^{\circ} \mathrm{C}$, with and without inhibitor.

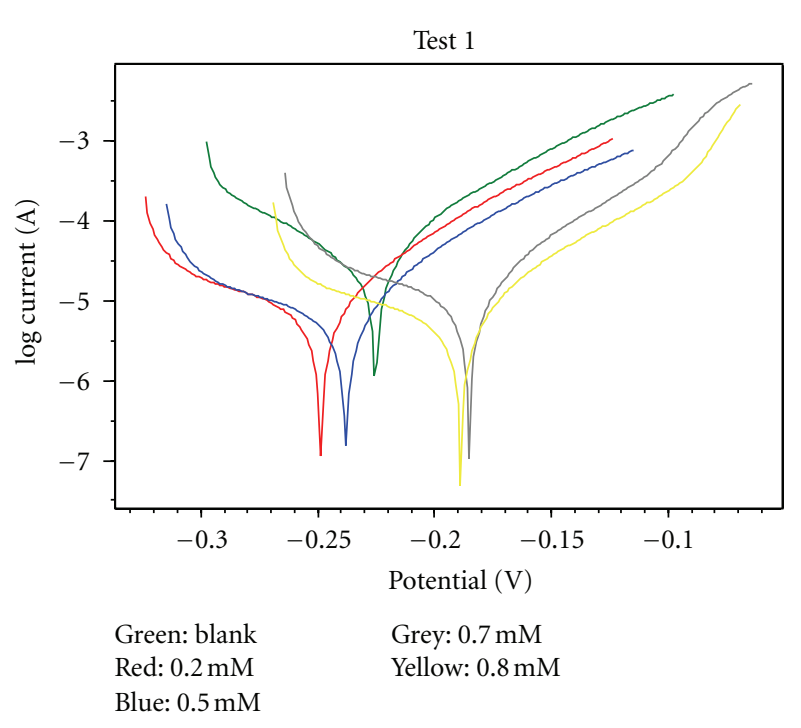

FIGURE 12: Tafel plots of copper specimens in $1 \mathrm{M} \mathrm{HCl}$ at $28^{\circ} \mathrm{C}$, with and without inhibitor.

inhibitor for MS specimens in $1 \mathrm{M} \mathrm{HCl}$. Similar results were reported by Li et al. [9].

Electrochemical polarization analysis on copper specimens showed a gradual decrease in the corrosion current densities. Inhibition efficiencies are comparable for copper specimens with the efficiencies obtained from EIS measurements. Anodic slopes $\left(b_{a}\right)$ are almost remained as constant but the cathodic Tafel slopes increased prominently, suggesting that the inhibitor molecules are more adsorbed on the cathodic site.

\section{Mechanism of Inhibition}

MS Specimens. It is well known that the surface of the metal is positively charged in acidic media [33]. It is believed that 
TABLE 5: Potentiodynamic polarization parameters of $\mathrm{MS}$ specimens in $1 \mathrm{M} \mathrm{HCl}$ at $28^{\circ} \mathrm{C}$ in the absence and presence of $3 \mathrm{FI} 4 \mathrm{ABA}$.

\begin{tabular}{lccccccc}
\hline & & \multicolumn{3}{c}{ Tafel data } & \multicolumn{3}{c}{ Linear polarization data } \\
$C(\mathrm{mM})$ & $E_{\text {corr }}(\mathrm{mV} / \mathrm{SCE})$ & $I_{\text {corr }}\left(\mu \mathrm{A} / \mathrm{cm}^{2}\right)$ & $b_{c}(\mathrm{mV} / \mathrm{dec})$ & $b_{a}(\mathrm{mv} / \mathrm{dec})$ & $\eta_{\mathrm{pol}} \%$ & $R_{p}(\mathrm{Ohm})$ & 18 \\
\hline 0 & -478 & 1062 & 106 & 78 & - & 57 \\
0.2 & -492 & 451 & 114 & 78 & 57.53 & 42 & 57 \\
0.5 & -482 & 64 & 101 & 64 & 93.97 & 265 & 93.2 \\
0.7 & -489 & 52 & 95 & 71 & 95.10 & 337 \\
0.8 & -491 & 22 & 87 & 66 & 97.93 & 733 \\
\hline
\end{tabular}

TABLE 6: Polarization parameters of copper specimens in $1 \mathrm{M} \mathrm{HCl}$ at $28^{\circ} \mathrm{C}$ in the absence and presence of 3FI4ABA.

\begin{tabular}{lccccccc}
\hline & & \multicolumn{3}{c}{ Tafel data } & \multicolumn{3}{c}{ Linear polarization data } \\
$C(\mathrm{mM})$ & $E_{\text {corr }}(\mathrm{mV} / \mathrm{SCE})$ & $I_{\text {corr }}\left(\mu \mathrm{A} / \mathrm{cm}^{2}\right)$ & $b_{c}(\mathrm{mV} / \mathrm{dec})$ & $b_{a}(\mathrm{mv} / \mathrm{dec})$ & $\eta_{\mathrm{pol}} \%$ & $R_{p}(\mathrm{Ohm})$ \\
\hline 0 & -225 & 32.75 & 63 & 63 & - & 355 & - \\
0.2 & -191 & 8.76 & 95 & 50 & 72.3 & 1101 & 67.8 \\
0.5 & -259 & 7.43 & 99 & 60 & 77.3 & 1644 & 78.4 \\
0.7 & -252 & 6.57 & 101 & 63 & 79.8 & 1958 \\
0.8 & -200 & 5.6 & 111 & 63 & 82.9 & 2177 \\
\hline
\end{tabular}

the $\mathrm{Cl}^{-}$ions could be specifically adsorbed on the metal surface and creates an excess of negative charge on the surface. This will favour the adsorption of protonated Schiff base $\left(3 \mathrm{FI} 4 \mathrm{ABAH}^{+}\right)$on the surface and hence reduce the dissolution of $\mathrm{Fe}$ to $\mathrm{Fe}^{2+}$ [34]. Besides this electrostatic interaction between the protonated Schiff base and the metal surface, other possible interactions are (i) interaction of unshared electron pairs in the molecule with the metal, (ii) interaction of $\pi$-electrons with the metal, and (iii) a combination of types (i-ii) $[35,36]$. If one examines the structure of Schiff base (3FI4ABA), many potential sources of inhibitor-metal interaction can be recognized. The unshared pair of electrons present on two $\mathrm{N}$ atoms is of key importance in making coordinate bond with the metal. The $\pi$-electron cloud of the aromatic rings and the azomethine linkage also participate in the inhibition mechanism. Furthermore, the double bonds in the inhibitor molecule permit the backdonation of metal $d$ electrons to the $\pi^{*}$ orbital, and this type of interaction cannot occur with amines [37]. This can be justified by the lower inhibition efficiency of the parent amine than that of Schiff base.

Copper Specimens. Anodic dissolution of copper is influenced by $\mathrm{Cl}^{-}$concentration. At an appreciable $\mathrm{Cl}^{-}$concentration, the dissolution of copper occurs through the formation of $\mathrm{CuCl}$ which will be transformed into soluble complex $\left[\mathrm{CuCl}_{2}\right]^{-}$. The soluble $\left[\mathrm{CuCl}_{2}\right]^{-}$may be oxidized to $\mathrm{Cu}^{2+}$ ions [38]. The addition of Schiff base will cause to lower the dissolution of the metal considerably by adsorption on the surface through the potential binding surface of the Schiff base. The lower value of inhibition efficiency for copper specimens can be attributed to the formation of strong complex between the Schiff base present in the solution and the $\mathrm{Cu}^{2+}$ ions formed by corrosion. The higher tendency of the Schiff base molecules to combine with the $\mathrm{Cu}^{2+}$ ions may cause to increase the dissolution of the metal. Formation of green-coloured complex having formula $\left[\mathrm{CuL}_{2}\left(\mathrm{H}_{2} \mathrm{O}\right)_{2}\right]$ inside the corrosion vessels is the justification of this argument.

\section{Conclusions}

(1) 3FI4ABA is a good inhibitor for $\mathrm{MS}$ in $1 \mathrm{M} \mathrm{HCl}$. A maximum of $98 \%$ of inhibition efficiency could be achieved with this inhibitor by Tafel polarization studies.

(2) Corrosion inhibition efficiency of the Schiff base 3FI4ABA is greater for mild steel than copper. This can be attributed to the strong tendency of Schiff base for complex formation with $\mathrm{Cu}^{2+}$ ions.

(3) Compared to the parent amine, 4-aminobenzoic acid, the Schiff base 3FI4ABA exhibited higher inhibition efficiencies for MS and copper.

(4) The inhibition mechanism is explained by adsorption. Adsorption of Schiff base on MS and copper surface obey the Langmuir isotherm.

(5) The thermodynamic parameters of the adsorption are calculated from the adsorption isotherms which showed that both physisorption and chemisorption are involved in the inhibition process.

\section{References}

[1] F. Bentiss, M. Traisnel, L. Gengembre, and M. Lagrenée, "Inhibition of acidic corrosion of mild steel by 3,5-diphenyl-4H1,2,4-triazole," Applied Surface Science, vol. 161, no. 1, pp. 194202, 2000.

[2] A. Raman and P. labine, Reviews on Corrosion Inhibitor Science and Technology, vol. 1, NACE, Houston, Tex, USA, 1986.

[3] E. E. Oguzie, "Corrosion inhibition of mild steel in hydrochloric acid solution by methylene blue dye," Materials Letters, vol. 59, no. 8-9, pp. 1076-1079, 2005.

[4] A. Yurt and Ö. Aykın, "Diphenolic Schiff bases as corrosion inhibitors for aluminium in $0.1 \mathrm{M} \mathrm{HCl}$ : potentiodynamic 
polarisation and EQCM investigations," Corrosion Science, vol. 53, no. 11, pp. 3725-3732, 2011.

[5] A. K. Singh, S. K. Shukla, M. Singh, and M. A. Quraishi, "Inhibitive effect of ceftazidime on corrosion of mild steel in hydrochloric acid solution," Materials Chemistry and Physics, vol. 129, no. 1-2, pp. 68-76, 2011.

[6] M. Behpour, S. M. Ghoreishi, N. Soltani, M. Salavati-Niasari, M. Hamadanian, and A. Gandomi, "Electrochemical and theoretical investigation on the corrosion inhibition of mild steel by thiosalicylaldehyde derivatives in hydrochloric acid solution," Corrosion Science, vol. 50, no. 8, pp. 2172-2181, 2008.

[7] K. S. Jacob and G. Parameswaran, "Corrosion inhibition of mild steel in hydrochloric acid solution by Schiff base furoin thiosemicarbazone," Corrosion Science, vol. 52, no. 1, pp. 224228,2010

[8] S. Deng, X. Li, and H. Fu, "Alizarin violet $3 \mathrm{~B}$ as a novel corrosion inhibitor for steel in $\mathrm{HCl}, \mathrm{H}_{2} \mathrm{SO}_{4}$ solutions," Corrosion Science, vol. 53, no. 11, pp. 3596-3602, 2011.

[9] X. Li, S. Deng, and H. Fu, "Blue tetrazolium as a novel corrosion inhibitor for cold rolled steel in sulfuric acid solution," Materials Chemistry and Physics, vol. 129, no. 3, pp. 696-700, 2011.

[10] A. Bansiwal, P. Anthony, and S. P. Mathur, "Inhibitive effect of some Schiff bases on corrosion of aluminium in hydrochloric acid solutions," British Corrosion Journal, vol. 35, no. 4, pp. 301-303, 2000.

[11] S. Li, S. Chen, S. Lei, H. Ma, R. Yu, and D. Liu, "Investigation on some Schiff bases as $\mathrm{HCl}$ corrosion inhibitors for copper," Corrosion Science, vol. 41, no. 7, pp. 1273-1287, 1999.

[12] ASTM, "Standard recommended practice for the laboratory immersion corrosion testing of metals," Tech. Rep. AST G-3172, ASTM, Philadelphia, Pa, USA, 1990.

[13] H. Ashassi-Sorkhabi, B. Shaabani, and D. Seifzadeh, "Effect of some pyrimidinic Shciff bases on the corrosion of mild steel in hydrochloric acid solution," Electrochimica Acta, vol. 50, no. 16-17, pp. 3446-3452, 2005.

[14] I. B. Obot and N. O. Obi-Egbedi, "Adsorption properties and inhibition of mild steel corrosion in sulphuric acid solution by ketoconazole: experimental and theoretical investigation," Corrosion Science, vol. 52, no. 1, pp. 198-204, 2010.

[15] M. A. Quraishi, D. Jamal, and M. Luqman, "Corrosion behaviour of VTS, STS and DTS inhibitors in formic and acetic acids," Indian Journal of Chemical Technology, vol. 9, no. 6, pp. 479-483, 2002.

[16] K. C. Emregül and O. Atakol, "Corrosion inhibition of iron in $1 \mathrm{M} \mathrm{HCl}$ solution with Schiff base compounds and derivatives," Materials Chemistry and Physics, vol. 83, no. 2-3, pp. 373-379, 2004.

[17] X. Li, S. Deng, H. Fu, and T. Li, "Adsorption and inhibition effect of 6-benzylaminopurine on cold rolled steel in $1.0 \mathrm{M}$ HCl," Electrochimica Acta, vol. 54, no. 16, pp. 4089-4098, 2009.

[18] E. Cano, J. L. Polo, A. L. A. Iglesia, and J. M. Bastidas, "A study on the adsorption of benzotriazole on copper in hydrochloric acid using the inflection point of the isotherm," Adsorption, vol. 10, no. 3, pp. 219-225, 2004.

[19] F. Bentiss, M. Lebrini, and M. Lagrenée, "Thermodynamic characterization of metal dissolution and inhibitor adsorption processes in mild steel/2,5-bis(n-thienyl)-1,3,4-thiadiazoles/ hydrochloric acid system," Corrosion Science, vol. 47, no. 12, pp. 2915-2931, 2005.

[20] W. H. Li, Q. He, S. T. Zhang, C. L. Pei, and B. R. Hou, "Some new triazole derivatives as inhibitors for mild steel corrosion in acidic medium," Journal of Applied Electrochemistry, vol. 38, no. 3, pp. 289-295, 2008.
[21] H. H. Hassan, E. Abdelghani, and M. A. Amin, "Inhibition of mild steel corrosion in hydrochloric acid solution by triazole derivatives. Part I. Polarization and EIS studies," Electrochimica Acta, vol. 52, no. 22, pp. 6359-6366, 2007.

[22] M. S. Abdel-Aal and M. S. Morad, "Inhibiting effects of some quinolines and organic phosphonium compounds on corrosion of mild steel in $3 \mathrm{M} \mathrm{HCl}$ solution and their adsorption characteristics," British Corrosion Journal, vol. 36, no. 4, pp. 253-260, 2001.

[23] P. Bommersbach, C. Alemany-Dumont, J. P. Millet, and B. Normand, "Formation and behaviour study of an environment-friendly corrosion inhibitor by electrochemical methods," Electrochimica Acta, vol. 51, no. 6, pp. 1076-1084, 2005.

[24] F. Mansfeld, "Recording and analysis of AC impedance data for corrosion studies," Corrosion, vol. 36, no. 5, pp. 301-307, 1981.

[25] I. L. Rosenfield, Corrosion Inhibitors, McGraw-Hill, New York, NY, USA, 1981.

[26] A. S. Priya, V. S. Muralidharam, and A. Subramannia, "Development of novel acidizing inhibitors for carbon steel corrosion in 15\% boiling hydrochloric acid," Corrosion, vol. 64, no. 6, pp. 541-552, 2008.

[27] M. El Azhar, B. Mernari, M. Traisnel, F. Bentiss, and M. Lagrenée, "Corrosion inhibition of mild steel by the new class of inhibitors [2,5-bis(n-pyridyl)-1,3,4-thiadiazoles] in acidic media," Corrosion Science, vol. 43, no. 12, pp. 2229-2238, 2001.

[28] A. Yurt, A. Balaban, S. U. Kandemir, G. Bereket, and B. Erk, "Investigation on some Schiff bases as $\mathrm{HCl}$ corrosion inhibitors for carbon steel," Materials Chemistry and Physics, vol. 85, no. 2-3, pp. 420-426, 2004.

[29] J. R. Macdonald, W. B. Johnson, and J. R. Macdonald, Theory in Impedance Spectroscopy, John Wiley \& Sons, New York, NY, USA, 1987.

[30] M. MaCafferty and N. Hackerman, "Double layer capacitance of iron and corrosion inhibition with polymethylene diamines," Journal of the Electrochemical Society, vol. 119, no. 2, pp. 146-154, 1972.

[31] X. Li, S. Deng, and H. Fu, "Synergism between red tetrazolium and uracil on the corrosion of cold rolled steel in $\mathrm{H} 2 \mathrm{SO} 4$ solution," Corrosion Science, vol. 51, no. 6, pp. 1344-1355, 2009.

[32] E. S. Ferreira, C. Giacomelli, F. C. Giacomelli, and A. Spinelli, "Evaluation of the inhibitor effect of L-ascorbic acid on the corrosion of mild steel," Materials Chemistry and Physics, vol. 83, no. 1, pp. 129-134, 2004.

[33] Q. Qu, Z. Hao, S. Jiang, L. Li, and W. Bai, "Synergistic inhibition between dodecylamine and potassium iodide on the corrosion of cold rolled steel in $0.1 \mathrm{M}$ phosphoric acid," Materials and Corrosion, vol. 59, no. 11, pp. 883-888, 2008.

[34] F. Bentiss, M. Traisnel, and M. Lagrenee, "The substituted 1,3,4-oxadiazoles: a new class of corrosion inhibitors of mild steel in acidic media," Corrosion Science, vol. 42, no. 1, pp. 127$146,2000$.

[35] D. P. Schweinsberg, G. A. George, A. K. Nanayakkara, and D. A. Steinert, "The protective action of epoxy resins and curing agents-inhibitive effects on the aqueous acid corrosion of iron and steel," Corrosion Science, vol. 28, no. 1, pp. 33-42, 1988.

[36] H. Shokry, M. Yuasa, I. Sekine, R. M. Issa, H. Y. El-Baradie, and G. K. Gomma, "Corrosion inhibition of mild steel by Schiff base compounds in various aqueous solutions: part 1," Corrosion Science, vol. 40, no. 12, pp. 2173-2186, 1998.

[37] A. K. Singh and M. A. Quraishi, "Inhibiting effects of 5substituted isatin-based Mannich bases on the corrosion of 
mild steel in hydrochloric acid solution," Journal of Applied Electrochemistry, vol. 40, no. 7, pp. 1293-1306, 2010.

[38] S. M. Milić and M. M. Antonijević, "Some aspects of copper corrosion in presence of benzotriazole and chloride ions," Corrosion Science, vol. 51, no. 1, pp. 28-34, 2009. 

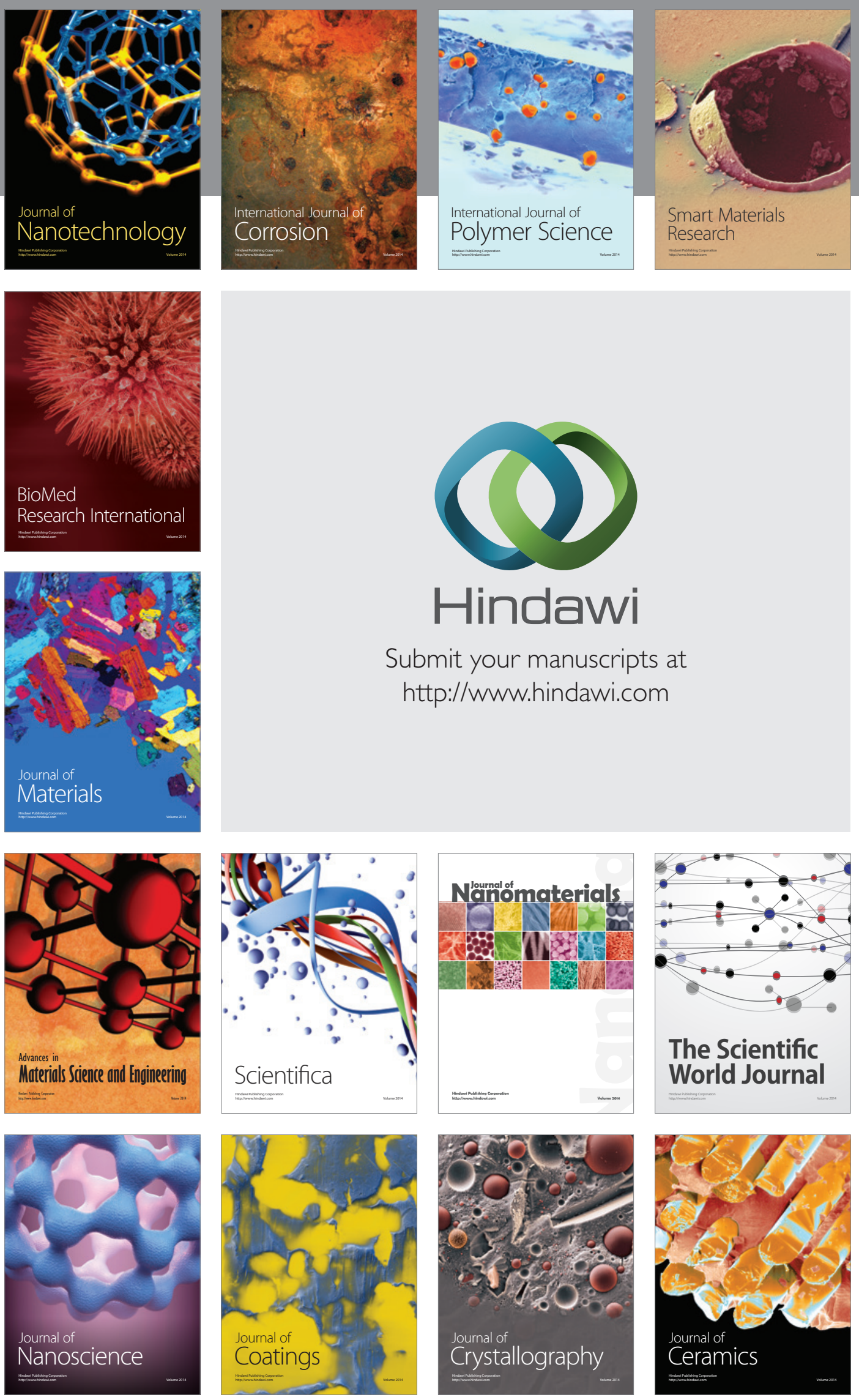

The Scientific World Journal

Submit your manuscripts at

http://www.hindawi.com

\section{World Journal}

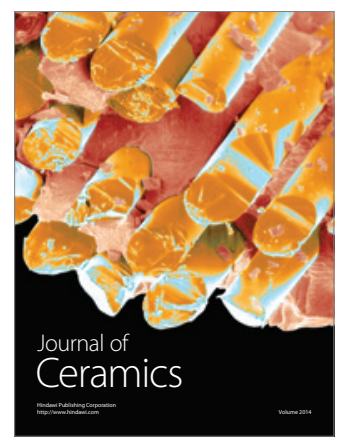

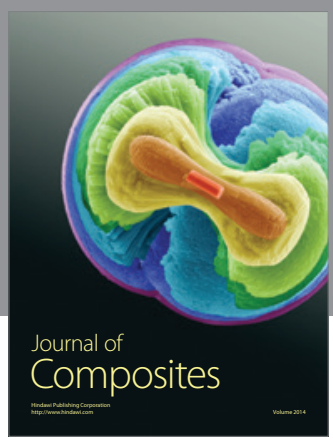
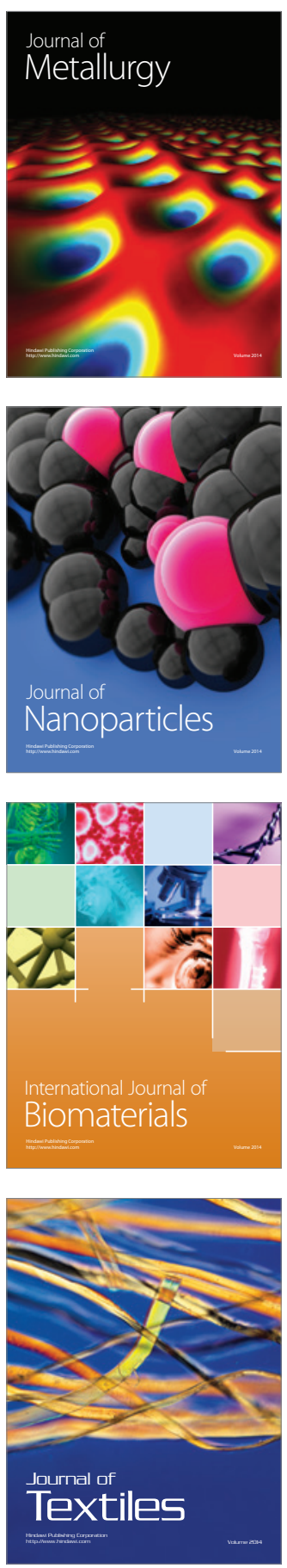